\title{
The Absence of Remotely Triggered Seismicity in Japan
}

\author{
by Rebecca M. Harrington and Emily E. Brodsky
}

\begin{abstract}
Remote dynamic triggering occurred in the western United States and Greece following the following the Denali, Hector Mine, Landers, and Izmit mainshocks in seismically active, largely geothermal areas that experienced shaking from the mainshock typically exceeding $0.2 \mathrm{~cm} / \mathrm{sec}$. Because triggered earthquakes are small (often below $M_{\mathrm{w}}, 2$ ), investigations of whether remote triggering is a generally occurring phenomena must be concentrated in well-instrumented locations. As a seismically active, geothermal, well-instrumented location, Japan constitutes an ideal location for such study. We systematically examine whether remote dynamic triggering occurs following mainshocks in Japan producing amplitudes in the study region above $0.2 \mathrm{~cm} / \mathrm{sec}$ at distances greater than two estimated fault lengths, from 1998 to 2004. We use both catalog data and filtered waveforms to search for seismicity increases. One significant regional increase follows a $M_{\mathrm{w}} 7.6$ mainshock in March 2000, largely due to a volcanic swarm that began the day before and increased in intensity in the following days. Two localized increases in cataloged seismicity occur in Kyushu, which is the only area in the study region with onshore tectonic extension. Two factors possibly inhibit regional triggering in Japan: (1) compressional tectonics, and (2) the frequent occurrence of large mainshocks. The ambient seismicity in Japan combined with the lack of observable widespread triggering renders rate-state friction and stress corrosion to be improbable triggering mechanisms. Fracture unclogging as a triggering mechanism is consistent with the observations.
\end{abstract}

\section{Introduction}

Remote dynamic triggering was observed following the $1992 M_{\mathrm{w}} 7.3$ Landers, California, the $1999 M_{\mathrm{w}} 7.1$ Hector Mine, California, the $1999 M_{\mathrm{w}} 7.4$ Izmit, Turkey, and the $2002 M_{\mathrm{w}} 7.9$ Denali, Alaska, earthquakes in seismically active, geothermal areas located hundreds of kilometers from the mainshock. In close proximity to the mainshock, both dynamic and static triggering mechanisms may induce failure; however, dynamic stress caused by the oscillatory motions of passing seismic waves dominates at farther distances (Hill et al., 1993; Brodsky et al., 2000; Kilb et al., 2000; Gomberg et al., 2001; Husen et al., 2004). To constrain the mechanisms of remote triggering, we must first understand if it is restricted to the western United States and Greece, or if it is a widely occurring phenomena. It is therefore useful to look for triggering in other seismically active, geothermal regions subjected to comparable mainshock shaking amplitudes. Because triggered earthquakes are usually detected with swarms of $M_{\mathrm{w}}<3$, triggered seismicity may be missed by global catalogs. For instance, the completeness threshold of the global ANSS catalog is $M_{\mathrm{w}} 4.5$, while the completeness for localized spatial regions such as the western United States is closer to $M_{\mathrm{w}} 2$. Therefore, a global study for longrange triggering is not yet practical. We must instead focus on areas with high-quality catalogs preferably supplemented with extensive digital waveforms to allow detailed analysis of the coda of large mainshocks.

Japan fits the above requirements admirably. The completeness threshold of the JMA catalog from 1998 to present is $M_{\mathrm{j}} 2$ as measured with a standard Gutenberg-Richter relation assuming a $b$-value of 1 . Waveforms are publicly available from both the Hi-Net (strong-motion) and F-Net (broadband) networks. Japan also has abundant geothermal areas and is very seismically active with over $11 M_{\mathrm{w}} \geq 7$ earthquakes in the last 7 years. Furthermore, there are isolated reports of regional triggering of local earthquakes by Oike and Matsumura (1984) and Ukawa et al. (2002) and, Miyazawa and Mori (2005) observe regional triggering of deep low-frequency events (DLPs) and shallow triggering at midrange distances in Hokkaido.

In this article, we systematically compare the regional seismicity following earthquakes with extensive shaking in Japan with comparable quakes in the western United States and Greece to determine if remote dynamic triggering occurs at similar levels. Seismicity levels are measured by searching (1) the Japanese Meteorological Agency (JMA) catalog for statistically significant increases in the background seismicity rate and (2) filtered waveforms from the Hi-net network for local, high-frequency earthquakes that may have been 
obscured by the mainshock coda and consequently missed by the catalog. We will show that long-range triggering does not occur in Japan at levels comparable to the United States. To explore the implications of this observation, we list major features that distinguish Japan from other triggering sites and discuss the implications these physical differences have for possible triggering mechanisms.

To perform a systematic check for long-range triggering in Japan, we examine the seismicity after all earthquakes from January 1998 through December 2004 that produced greater than $0.2 \mathrm{~cm} / \mathrm{sec}$ shaking in Japan at distances greater than 2 fault lengths (Table 1, Fig. 1). Using broadband Fnet waveforms to check local surface shaking, we found that of the 31 earthquakes in Japan with $M_{\mathrm{w}} \geq 6.5$ listed in the Harvard CMT catalog during this period, the 15 listed in Table 1 meet the shaking criteria. The list in Table 1 is not sensitive to the details of the shaking criterion as it does not change for variations of $\pm 0.1 \mathrm{~cm} / \mathrm{sec}$. All previous longrange triggering episodes in the western United States and Greece had at least $0.2 \mathrm{~cm} / \mathrm{sec}$ of local shaking, so our threshold is comparable (Prejean et al., 2004). With the exception of the Sumatra mainshock, the shaking criterion corresponds to the following depth and magnitude guidelines: $M_{\mathrm{w}} 6.7-6.9$ with depths less than $50 \mathrm{~km}$, and $M_{\mathrm{w}} 7$ or greater with depths less than $100 \mathrm{~km}$, between latitudes of $20^{\circ} \mathrm{N}$ to $50^{\circ} \mathrm{N}$ and $120^{\circ} \mathrm{E}$ and $150^{\circ} \mathrm{E}$.

\section{Catalog Study}

Since we are studying long-range dynamic triggering and comparing it to crustal occurrences in Greece and the

Table 1

Mainshocks Considered as Candidates to Possibly Have Caused Remote Dynamic Triggering in Japan

\begin{tabular}{|c|c|c|c|c|c|c|}
\hline $\begin{array}{l}\text { Mainshock } \\
\text { (mm/dd/yyyy) }\end{array}$ & Latitude & Longitude & $\begin{array}{c}\text { Depth } \\
(\mathrm{km})\end{array}$ & $\begin{array}{l}\text { Plunge } \\
\text { T/B Axes } \\
\text { (Harvard } \\
\text { CMT) }\end{array}$ & $\begin{array}{l}\text { Near- } \\
\text { Field } \\
\text { Limit } \\
(\mathrm{km})\end{array}$ & $\begin{array}{c}M_{\mathrm{w}} \\
\text { (Harvard } \\
\text { CMT) }\end{array}$ \\
\hline (a) $12 / 26 / 2004$ & 3.09 & 94.26 & 28.6 & $52 / 3$ & 720 & 9.0 \\
\hline (b) $11 / 28 / 2004$ & 42.86 & 145.37 & 49.4 & $64 / 15$ & 70 & 7.0 \\
\hline (c) $9 / 05 / 2004$ & 33.13 & 137.22 & 12.0 & $77 / 13$ & 110 & 7.4 \\
\hline (d) $9 / 05 / 2004$ & 32.94 & 137.00 & 16.0 & $80 / 6$ & 90 & 7.2 \\
\hline (e) $10 / 31 / 2003$ & 37.89 & 142.68 & 15.0 & 54 & 70 & 7.0 \\
\hline (f) $10 / 08 / 2003$ & 42.48 & 144.82 & 36.0 & $59 / 11$ & 50 & 6.7 \\
\hline (g) $9 / 25 / 2003$ & 42.21 & 143.84 & 28.2 & $53 / 7$ & 320 & 8.3 \\
\hline (h) $5 / 26 / 2003$ & 38.94 & 141.57 & 61.0 & $62 / 6$ & 70 & 7.0 \\
\hline (i) $3 / 24 / 2001$ & 33.97 & 132.52 & 47.4 & $10 / 19$ & 60 & 6.8 \\
\hline (j) $10 / 06 / 2000$ & 35.33 & 133.20 & 15.0 & $6 / 83$ & 50 & 6.7 \\
\hline (k) $8 / 04 / 2000$ & 48.77 & 142.03 & 15.0 & $69 / 17$ & 60 & 6.8 \\
\hline (1) $3 / 28 / 2000$ & 22.32 & 143.76 & 99.7 & $40 / 4$ & 140 & 7.6 \\
\hline (m) $1 / 28 / 2000$ & 43.08 & 146.81 & 50.0 & $42 / 37$ & 60 & 6.8 \\
\hline (n) $9 / 20 / 1999$ & 24.15 & 120.80 & 21.2 & $70 / 2$ & 140 & 7.6 \\
\hline (o) $5 / 03 / 1998$ & 22.37 & 125.53 & 22.9 & $6 / 82$ & 110 & 7.4 \\
\hline
\end{tabular}

All of these mainshocks produced shaking amplitudes exceeding 0.2 $\mathrm{cm} / \mathrm{sec}$ at distances $>2$ fault lengths. The $0.2 \mathrm{~cm} / \mathrm{sec}$ cutoff is the lower amplitude threshold of shaking observed with triggered seismicity in the Western United States (Prejean et al., 2004). western United States, we limit the catalog to crustal events $(<33 \mathrm{~km})$ greater than two fault-lengths from the mainshock epicenter. Our results vary only if we include seismicity within one fault length - namely, within the traditional aftershock zone. The two fault-length minimum minimizes any ambiguity as to whether events at this distance could be considered part of a regular near-field aftershock sequence. Fault lengths are computed from the seismic moment using the standard relationship for a circular crack with stress drops of $3 \mathrm{MPa}$ (Scholz, 2002).

Figure 2 shows the seismicity meeting these criteria following each of the earthquakes in Table 1. Figure $2 b(1)$ is magnified to show a peak centered on the day after the mainshock resulting from the eruption at Mount Usu. The eruption swarm started the day before with less than 20 earthquakes and increased in intensity, having 89 on the day of the mainshock and nearly 400 the day after. No other peaks in Figure $2 b$ as are obvious as those in Figure $2 a$, which show the comparable data for the western United States and Greece.

We further process the catalog before testing for triggering by eliminating clearly unrelated volcanic swarms. The May 1998 earthquake (o) coincides with a swarm on the eastern Izu peninsula that peaks in intensity and abates before the mainshock. We remove this swarm and one other like it in August 2000 [mainshock (k)] at Miyakejima associated with magma movement culminating in an eruption well before the mainshock (Global Volcanism Program). Note that the seismicity of last two swarms climaxes well before the mainshock and so certainly should be eliminated from the current triggering study.

We compute the significance level using an empirical probability distribution function for the catalog over the

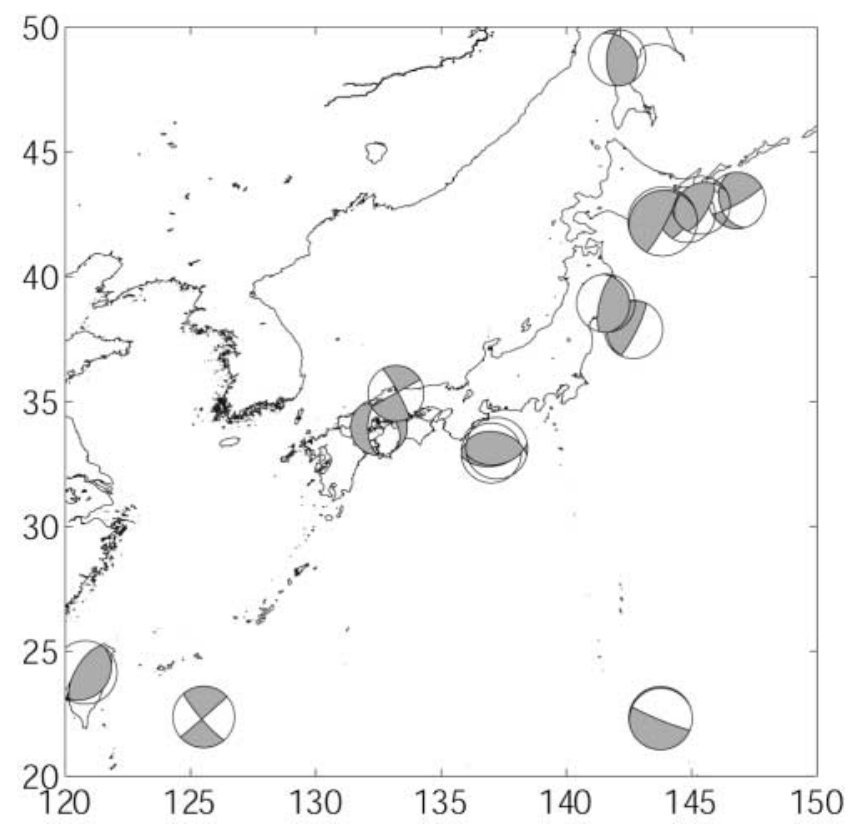

Figure 1. Mainshocks from Table 1. 
study period and measure the probability of the observed number of earthquakes in Figure 2 occurring by chance. The null hypothesis is that the seismicity on the first day following the mainshocks is ordinary, that is, at the $95 \%$ confidence level seismicity is not elevated.

Other than the Mount Usu eruption, we do not observe any examples of elevated seismicity at the $95 \%$ confidence level in Figure 2a. This is also true if seismicity bins are $1 \mathrm{hr}$ or 1 week. Documented triggering at volcanoes in Japan suggests that the mainshock waves might have caused the nascent swarm in March 2000 to increase in intensity and result in an eruption (Ukawa, 2000). However, even if the swarm was linked, a 1/15 observed occurrence rate does not reject the null hypothesis because the chance of finding at least 1 occurrence of seismicity elevated at the $95 \%$ level out of 15 trials is 54\% (Blom, 1989). In contrast, we can reject the null hypothesis using the same parameters in the western United States and Greece. Anomalous seismicity occurs on the days of the mainshocks above the 95\% level, except for the Hector Mine, California, earthquake, which produced an increase at the $86 \%$ level (corresponding to 32 events). However, seismicity increased above the $95 \%$ level on the second day after the mainshock (72 events).

In order to make certain that we are not missing anything by devising an overly restrictive significance test, we delve into some obvious alternative hypotheses. We explore the possibility of elevated seismicity in a restrictive subsection of Japan, and/or delayed by a day (like Hector Mine). We even check for a small signal below the formal completeness threshold of the catalog, as has been occasionally seen for other earthquakes (Brodsky et al., 2000).

Kyushu is an ideal restricted subsection to check because it is heavily populated with geothermal fields (Agency of Natural Resources and Energy and Geological Survey of Japan, 1976). Figure 3 shows the seismicity in Kyushu following each mainshock of Table 1. The strongest shaking in the subregion came from the Sumatra earthquake, and in the following $24 \mathrm{hr}$, 11 out of the 35 earthquakes above the completeness threshold in Japan occur in Kyushu. The peak in Figure 3a corresponds to 95.1\% significance. The pair of earthquakes in Figure $3 \mathrm{c}$ and $\mathrm{d}$ result in peaks that are at the 94.5\% significance, that is, just below our threshold. The elevated seismicity for earthquakes (Fig. 3c,d) begins in the hour after the later, larger mainshock. The peak in Figure 31 in the day following the mainshock is predominantly from the Ibusuki Volcano field in southern Kyushu. A local catalog from the Fukuoka observatory confirms that the swarm begins at 30 March 15:00:00 local time, nearly 43 hours after the mainshock, that is, beyond the 24 hours window of our statistical test. We formally observe that $1 / 15$ cases have seismicity in Kyushu above the $95 \%$ level; that is, the null hypothesis cannot be rejected. A more generous null hypothesis exploring elevated seismicity above the $94 \%$ level results in 3/15 occurrences, which still does not reject the null hypothesis. So for levels of shaking comparable to the western United States, Kyushu does not consistently trigger, but intriguingly for the very highest shaking case, Sumatra, there may be a signal.

Small earthquakes may be completely recorded in isolated, densely instrumented areas even if the entire catalog is not complete at the small magnitudes. Because of the abundance of small earthquakes, they may contain a signal that would otherwise be hidden. The 9/25/2003 event particularly deserves close scrutiny because Miyazawa and Mori (2005) report deep low-frequency and intermediate range (1-2 fault lengths) triggering following this event. We therefore check the seismicity below the completeness threshold for Tokachi-oki. Including events $M_{\mathrm{j}} \geq 1$ results in only a slight increase in regional seismicity that is still well below the 95\% seismicity level (Fig. 4).

\section{Waveform Study}

Using methods similar to others, we bandpass Hi-net and F-net waveforms at 5 to $20 \mathrm{~Hz}$ to search for local events at Hi-Net network stations for the hour before and after the two largest mainshocks, (a) Sumatra, and (g) Tokachi-oki, namely when we expect the catalog to be depleted because of the mainshock coda (Brodsky et al., 2000; Gomberg et al., 2004; Husker and Brodsky, 2004; Prejean et al., 2004). The 1-hr time window is sufficient because the mainshocks swamped the catalog for 50 and $20 \mathrm{~min}$, respectively, after which the catalog should return to normal completeness levels.

We used the Antelope Seismic System software to pick, associate, and filter (high pass of $5 \mathrm{~Hz}$ ) all three components of 687 stations in the Hi-net network (with sample rates of $100 \mathrm{~Hz}$ ) following the two mainshocks. There were no additional events outside of the catalog following Tokachi-oki and two events in Honshu not located by the catalog following Sumatra. An estimation of magnitude using $P-S$ arrival time and amplitude revealed that the missing events were below the catalog completeness. Filtered waveforms of Hinet station YKW in southern Kyushu reveal a burst of microseismicity commencing with the peak amplitude Rayleigh-wave shaking of the Sumatra mainshock. Additionally, we searched by hand $27 \mathrm{~F}$-net stations (with sample rates of $80 \mathrm{~Hz}$ ) for the remaining mainshocks and found no indication of local seismicity increases.

\section{Physical Conditions for Triggering}

Shaking amplitudes over most of Japan following Tokachi-oki and Sumatra exceed triggering amplitudes in the western United States, yet we observed no compelling evidence of triggering (Fig. 5). So now we attempt to identify what physical features make Japan a less effectively triggered region. We focus on the mechanistic implications of the two most notable geophysical factors that differentiate Japan from the western United States and Greece: (1) Japan experiences a higher level of seismicity and (2) Japan is predominantly in a compressional tectonic regime. 
Denali, $11 / 3 / 2002$

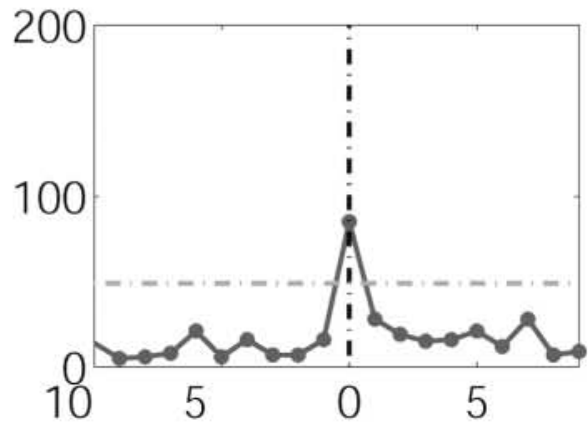

Izmit, 8/17/1999

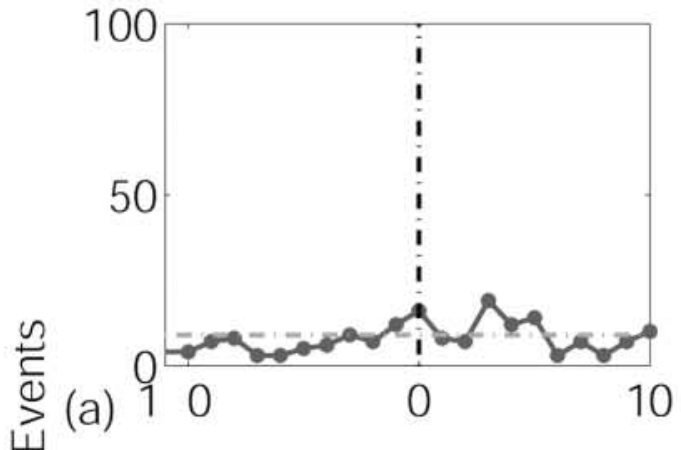

Hector Mine, 10/16/1999

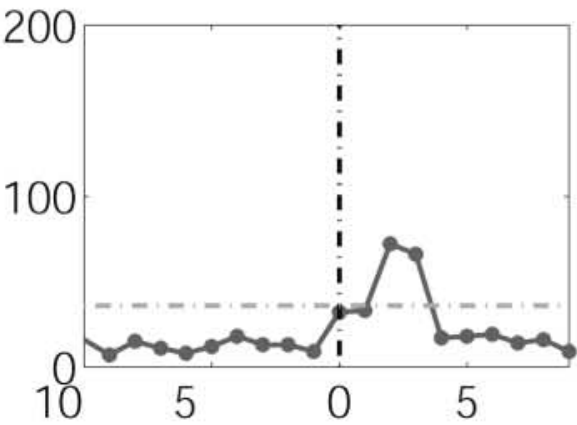

Landers, 6/28/1992

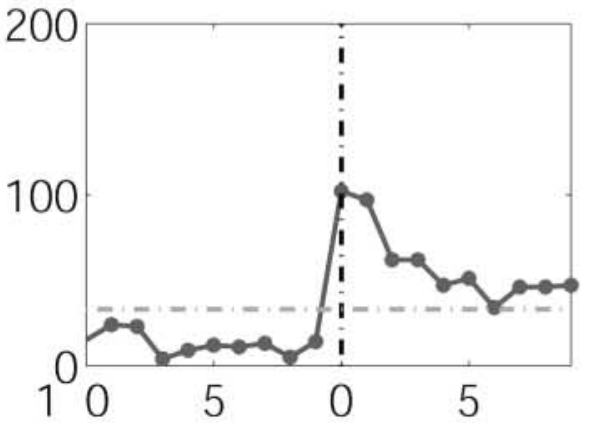

(a) $12 / 26 / 2004$

(b) $11 / 28 / 2004$

(c) $9 / 5 / 2004$

(d) $9 / 5 / 2004$
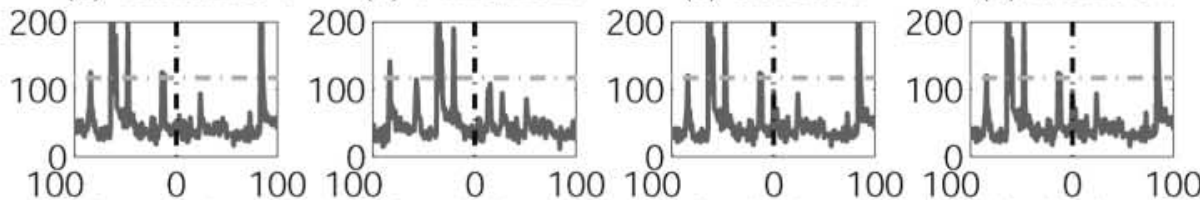

(e) $10 / 31 / 2003$

(f) $10 / 8 / 2003$
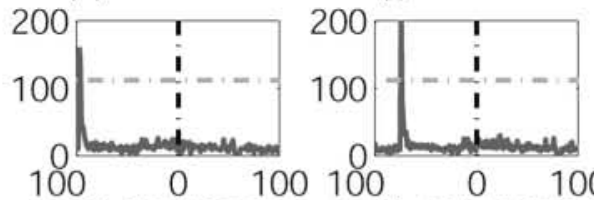

(g) $9 / 25 / 2003$

(h) $5 / 26 / 2003$
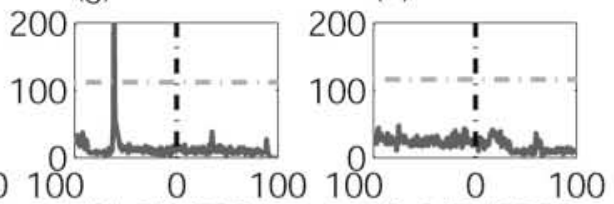

(i) $3 / 24 / 2001$

(j) $10 / 6 / 2000$

(k) $8 / 4 / 2000$

(I) $3 / 28 / 2000$
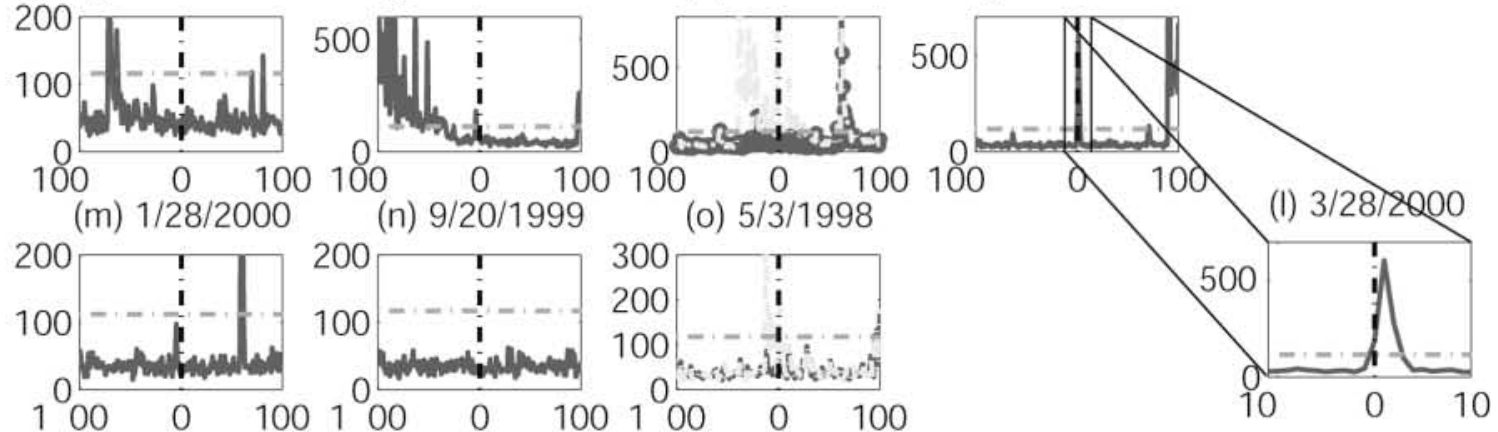

(b)
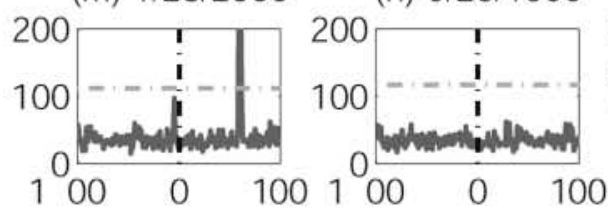

(o) $5 / 3 / 1998$

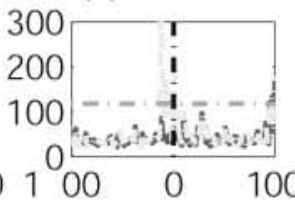

Days from Mainshock

Figure 2. (a) Histogram of the cataloged seismicity in the western United States and Greece. Seismicity is separated the events in 24-hr time bins, time-shifted to mainshock at time zero. We count earthquakes outside the near field limit and above $M_{\mathrm{j}}$ 2. (b) The same plot as (a) for the same-sized region in Japan. Green dashed lines represent seismicity including unrelated volcanic swarms (see text). Blue lines include all seismicity beyond $40 \mathrm{~km}$ from the volcanic eruption locations (and beyond two fault lengths). Red lines indicate the $95 \%$ significance level. The zoom on (1) shows the resultant peak of an eruption at Mt. Usu, which increased in intensity after the mainshock. 


\section{Cataloged Seismicity in Kyushu}

(a) $12 / 26 / 2004$

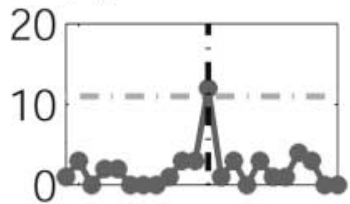

(e) $10 / 31 / 2003$

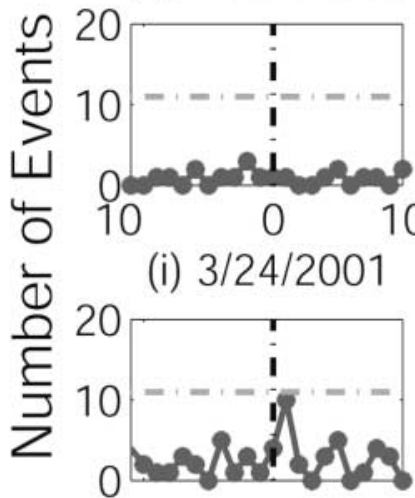

(m) $1 / 28 / 2000$

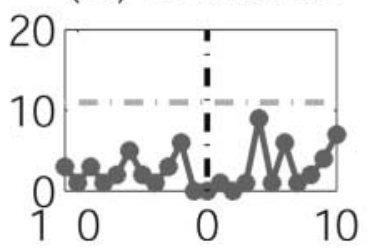

(b) $11 / 28 / 2004$

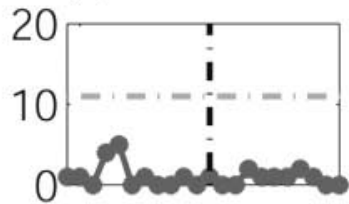

(f) $10 / 8 / 2003$

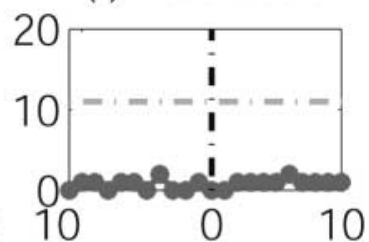

(j) $10 / 6 / 2000$

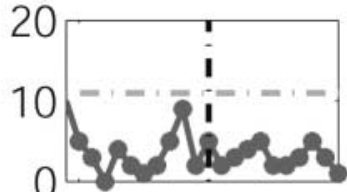

(n) $9 / 20 / 1999$

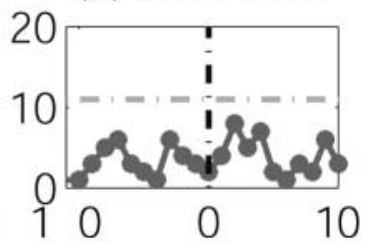

Days from Mainshock (c) 9/5/2004, M 7.4 (d) 9/5/2004, M 7.2

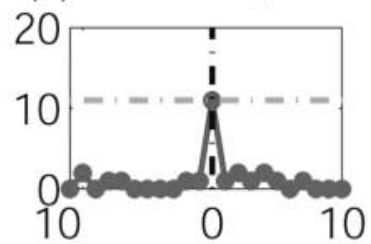

(g) $9 / 25 / 2003$

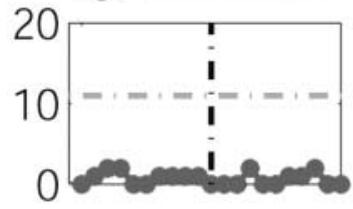

(k) $8 / 4 / 2000$

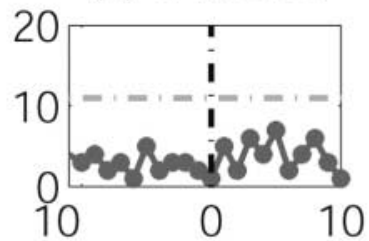

(o) $5 / 3 / 1998$

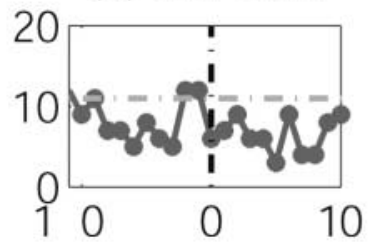

10

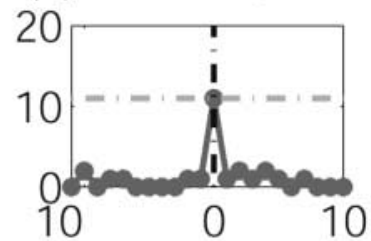

(h) $5 / 26 / 2003$

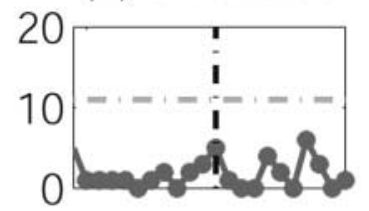

(I) $3 / 28 / 2000$

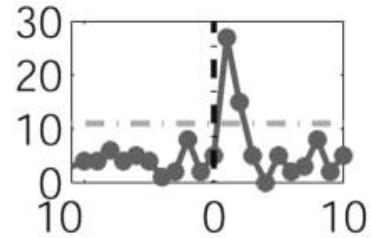

10

Figure 3. Cataloged seismicity within the circle on Figure 5 of $M_{\mathrm{j}}>2$ in Kyushu, the region in Japan with notable onshore extensional strain (Kato et al., 1998). Red dashed lines indicate the $95 \%$ significance level. A statistically significant seismicity increase of $95.1 \%$ occurs on the day of the 12/26/2004 Sumatra mainshock (corresponding to 11 events). The peaks in (c) and (d) are at the $94.5 \%$ significance. Mainshock (c) comes roughly $5 \mathrm{hr}$ after (d), and separating seismicity in hour time bins indicates that the peak comes after (c), the larger event. A swarm of seismicity occurs at the Ibusuki Volcano field the second day after the March 2000 mainshock-see text for discussion.

\section{High Ambient Seismicity}

From January 1998 to January 2005, there are 15 events that shook a large portion of Japan at amplitudes exceeding $0.2 \mathrm{~cm} / \mathrm{sec}$, while in the same period only 3 earthquakes produced comparable shaking in a section of the western United States the same size as Japan (Tables 1 and 2). Therefore, Japan is shook harder and more often.

The dominant proposed mechanisms for long-range triggering are acceleration of friction instabilities as governed by the constitutive law of rate-state friction (Dieterich, 1994), subcritical crack growth by stress corrosion (Brodsky et al., 2000; Gomberg 2001), and unclogging of fractures (Brodsky et al., 2003). In the absence of any other compli- cating factors, the lack of triggering in a high seismicity environment is consistent with only the third of these mechanisms.

According to the Dieterich (1994) theory of rate-state frictionally governed earthquake nucleation, the seismicity rate after a perturbance, $R$, is proportional to steady state seismicity, $r$. For instance, the instantaneous rate-change at the time of a stress step $\Delta \tau$ is predicted to be

$$
R=r \exp \left(\frac{\Delta \tau}{A \sigma}\right)
$$

where $A$ is a material property and $\sigma$ is the normal stress, 


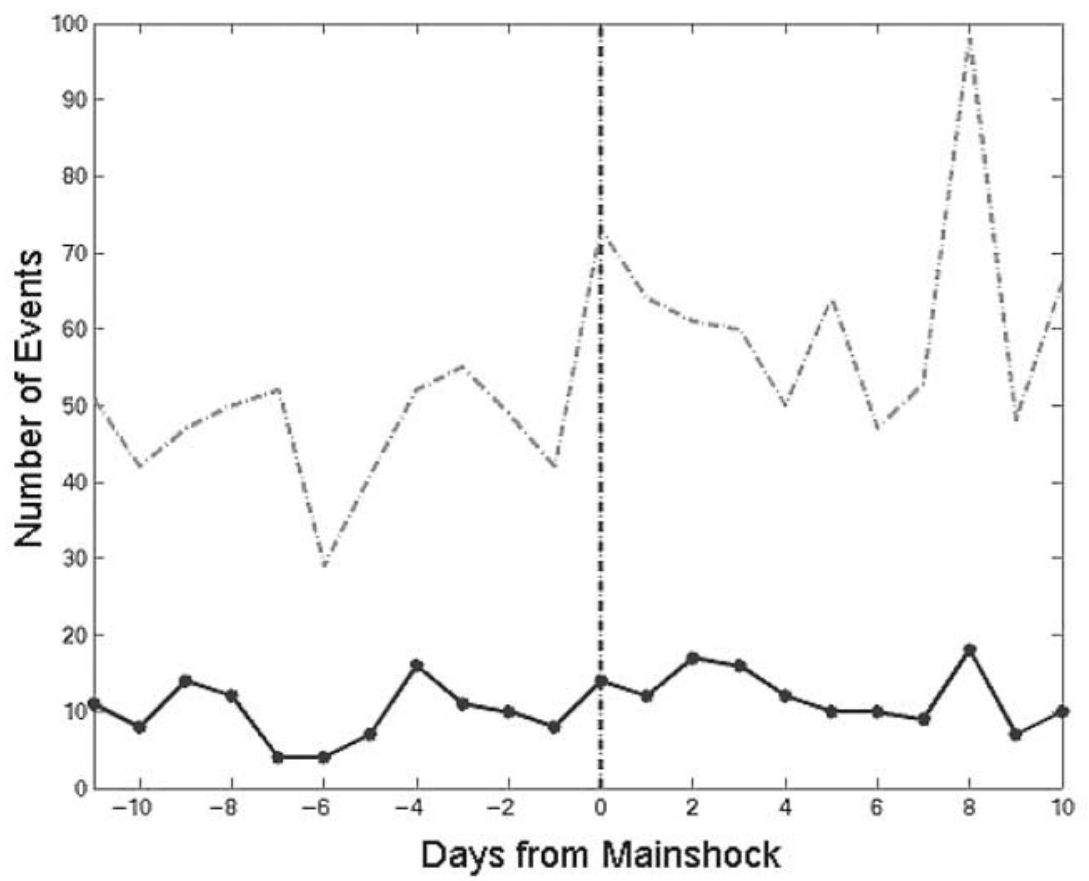

Figure 4. Histogram of seismicity in Japan 10 days before and after the $(\mathrm{g}) 9 / 25 / 2003, M_{\mathrm{w}}$ 8.3 Tokachi-oki mainshock. The dashed histogram indicates events that are $M_{\mathrm{j}}>1$, and the solid histogram with asterisks indicates event of $M_{\mathrm{j}}>2$. All events lay outside of 320 $\mathrm{km}$ (two fault lengths) from the epicenter.

\section{Radial Amplitude Contour (cm/s)}

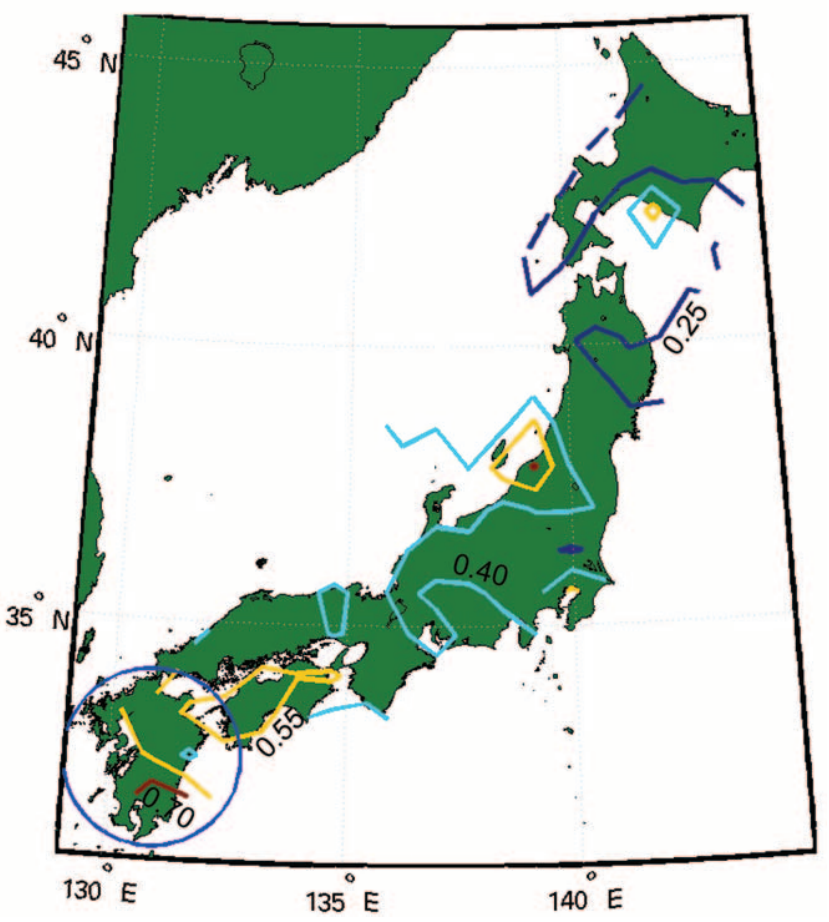

Figure 5. Contour plot of shaking amplitudes for the $12 / 26 / 2004$ Sumatra mainshock, taken from the 687-station Hi-net borehole network. Contour amplitudes are in $\mathrm{cm} / \mathrm{sec}$. Transverse and vertical components exhibit similar shaking amplitudes. The circle around Kyushu shows the restricted catalog region of Figure 3. which is assumed constant (Dieterich, 1994). Given equation (1), we would expect to see large rate changes in seismicity given a high background rate, contrary to what we observe.

A similar result applies for stress corrosion. Brodsky and Prejean (2005) show that the equations governing stress corrosion or subcritical crack growth are identical to the governing equation for evolution of faults with rate-state stress in the commonly applied limits of exponential state evolution near failure (Dieterich, 1994). Therefore, if the background rate is proportional to the stressing rate and earthquakes are generated by subcritical crack growth via stress corrosion, the high background seismicity rate of Japan should have resulted in many triggered earthquakes.

Brodsky et al. (2003) suggest that the network of clogged fractures within saturated hydrological units coupled with the constant precipitation of material into fractures from geothermal fluids make these regions susceptible to triggering effects via fracture unclogging from the dynamic stresses imposed by the waves of distant earthquakes. More shaking activity in a region should constantly disturb the fragile blockages in fractures and faults, preventing the formation of long-term obstacles to fluid flow. With frequent shaking, there is no chance to build or maintain a differential pressure between hydrological units and therefore the opportunity to trigger seismicity is eliminated.

\section{Tectonic Regime}

Unlike the western United States and Greece, Japan lies on a convergent plate boundary. GPS data indicates that all of the Japanese islands with the exception of Kyushu occupy a dominantly compressional tectonic regime (see figures 3 and 5 of Kato et al., 1998). The same data indicates that the 
Table 2

Mainshocks that Dynamically Triggered Remote Seismicity in the Western United States and Greece

\begin{tabular}{ccccccc}
\hline $\begin{array}{c}\text { Mainshock } \\
(\mathrm{mm} / \mathrm{dd} / \text { yyyy) }\end{array}$ & Latitude & Longitude & $\begin{array}{c}\text { Depth } \\
(\mathrm{km})\end{array}$ & $\begin{array}{c}\text { Plunge } \\
\text { T/B Axes }\end{array}$ & $\begin{array}{c}\text { Limit } \\
(\mathrm{km})\end{array}$ & $M_{\mathrm{w}}$ \\
\hline $11 / 03 / 2002$ & 63.23 & -144.89 & 15.0 & $19 / 69$ & 200 & 7.9 \\
$10 / 16 / 1999$ & 34.71 & -116.27 & 15.0 & $11 / 79$ & 80 & 7.1 \\
$8 / 17 / 1999$ & 41.01 & 29.97 & 17.0 & $13 / 73$ & 140 & 7.6 \\
$6 / 28 / 1992$ & 34.65 & -116.65 & 15.0 & $9 / 68$ & 100 & 7.3 \\
\hline
\end{tabular}

All of the mainshocks have steeply plunging $B$ axes, suggesting strikeslip earthquakes. In contrast, the Japan mainshocks are mostly thrust events with shallowly plunging $B$ axes.

strain in the western half of Kyushu is dominantly extensional. Since observed triggering occurs in locally extensional areas, one might ask whether remote dynamic triggering requires a locally extensional regime. Extensional tectonics have implications for both the types of mainshocks produced and the stress regimes of the triggerable faults.

Mainshock Focal Mechanism. Since strike-slip earthquakes may radiate more energy than thrust-style events (Choy and Boatright, 1995), perhaps they are more effective triggerers. Given that the earthquakes in Japan with the largest shaking amplitudes-Tokachi-oki and Sumatra-were thrust events, it is possible that the triggering mainshocks in the United States, which all had strike-slip focal mechanisms, trigger microseismicity more effectively because of radiation effects (Table 2 ).

We test this hypothesis by directly comparing the level of shaking between the large thrust events in Japan and the Denali earthquake. Figure 5 indicates that the raw shaking amplitudes from Sumatra over the entire study area are in fact comparable with those observed to cause triggering in the western United States at locations like the Geysers, Long Valley, and Coso Geothermal field (Prejean et al., 2004; Brodsky and Prejean, 2005). Furthermore, the shaking in Japan in a range of frequency bandwidths is larger than or comparable to amplitudes observed in the western United States over all bandwidths (Table 3). From the point of view of the resultant shaking, thrust-style mainshocks in Japan should trigger seismicity as effectively as strike-slip mainshocks in the western United States, yet they do not.

Stress Regime and Triggering. According to Anderson's theory of faulting, the overall stress in a thrust environment is higher because the principle compressive stress is horizontal. Therefore, a region of thrust faulting requires a higher differential stress for a thrust fault to rupture (Sibson, 1974). If considering only stress regime, remote dynamic triggering should occur more readily in regions of localized extension, where faults are weaker.

If extension is a prerequisite to being triggerable, we might expect to see different triggering behavior in Kyushu
Table 3

Maximum Horizontal Shaking Amplitudes in Japan and at Two Triggered Sites in the Western United States.

\begin{tabular}{lccc}
\hline & $>5 \mathrm{~Hz}$ & $0.1-5 \mathrm{~Hz}$ & $<0.1 \mathrm{~Hz}$ \\
\hline (a) $12 / 26 / 2004$ & - & $0.06 \mathrm{~cm} / \mathrm{sec}$ & $0.7 \mathrm{~cm} / \mathrm{sec}$ \\
(g) $9 / 25 / 2003$ & - & $0.07 \mathrm{~cm} / \mathrm{sec}$ & $0.6 \mathrm{~cm} / \mathrm{sec}$ \\
(i) $3 / 24 / 2001$ & $0.7 \mathrm{~cm} / \mathrm{sec}$ & $3.5 \mathrm{~cm} / \mathrm{sec}$ & $0.2 \mathrm{~cm} / \mathrm{sec}$ \\
(j) $10 / 06 / 2000$ & $0.1 \mathrm{~cm} / \mathrm{sec}$ & $3.7 \mathrm{~cm} / \mathrm{sec}$ & $0.2 \mathrm{~cm} / \mathrm{sec}^{*}$ \\
NEW (Washington) & - & $2 \mathrm{~cm} / \mathrm{sec}^{*}$ & $1.5 \mathrm{~cm} / \mathrm{sec}^{*}$ \\
HLID (Haley, Idaho) & $.01 \mathrm{~cm} / \mathrm{sec}^{*}$ & $0.6 \mathrm{~cm} / \mathrm{sec}^{*}$ & $0.5 \mathrm{~cm} / \mathrm{sec}^{*}$ \\
\hline
\end{tabular}

The letters in the first column refer to the events in Table 1. Stations in Japan are located outside of five fault lengths as defined in the text. Shaking amplitudes for stations in the United States result from the Denali mainshock. We selected band passes to isolate the major components of shaking that could conceivably have different physical effects: high-frequency scattering, intermediate period body waves, and long-period surface waves. Seismic amplitudes from mainshocks in Japan are comparable in all frequency bands to amplitudes in the western United States that triggered seismicity.

*Record off-scale for E components, so the amplitude indicated is a lower limit.

and the rest of Japan since the western half of Kyushu comprises the only onshore (i.e., instrumented) extensional region. In fact, this difference might be observed on the day of the Sumatra mainshock (Fig. 3a). However, we cannot reject the null hypothesis with this isolated, marginal case. While this hint of triggering in Figure 3a (and possibly Fig. $3 c)$ because it implies extensional tectonics might be important, the increase is marginal compared with the increases observed in the western United States and do not suggest widespread triggering. Some localized triggered areas in the western United States experienced more than 60 earthquakes following Denali (97.2\% significance).

\section{Conclusions}

Our study indicates that remote dynamic triggering does not occur in Japan at high levels. Isolated remote, dynamic triggering may exist, but catalog and waveform data indicate that any excess seismicity is below the levels observed in the western United States and Greece even though there are at least 15 well-recorded Japanese earthquakes that produced shaking on the order of the Greek and American mainshocks. Two factors, which may work either separately or in combination, differentiate Japan from other triggered locations: (1) a high seismicity rate with more $M_{\mathrm{w}}>7$ earthquakes occurring in the region and (2) tectonic compression. The higher background seismicity rate but lower level of triggered seismicity is inconsistent with the well-studied ratestate triggering mechanism, suggesting that another mechanism is more important. The lack of extensive triggering in geothermal regions is consistent with fracture unclogging as a triggering mechanism because the faults and fractures may be consistently unclogged in the presence of frequent largeamplitude, low-frequency shaking from large mainshocks. In this scenario the high seismicity rate inhibits remote dy- 
namic triggering on a regional scale in Japan to the extent observed in the western United States and Greece following mainshocks that produce comparable dynamic stresses at comparable distances. The marginally significant triggering in Kyushu suggests the importance of tectonic extension encouraging triggering. We conclude that either, or possibly both, fracture unclogging and wide-ranging compressional tectonics inhibit remote dynamic triggering.

\section{Acknowledgments}

We used seismic data from the Fukuoka Observatory, the Japan Meteorological Agency, and the National Research Institute for Earth Science and Disaster Prevention (the Hi-net and F-net seismic networks). These data have been provided by the National Research Institute for Earth Science and Disaster Prevention, Hokkaido University, Hirosaki University, Tohoku University, the University of Tokyo, Nagoya University, Kyoto University, Kochi University, Kyushu University, Kagoshima University, National Institute of Advanced Industrial Science and Technology, and the Tokyo Metropolitan Government. Thanks to Kazushige Obara and Masatoshi Miyazawa for supplying JMA catalog data, as well as thanks to Osamu Nakagome from the Fukuoka Observatory for supplying additional catalog data. We thank H. Kanamori and S. Prejean for instructive comments on an early draft. We would also like to thank two anonymous reviewers for their constructive comments, which vastly improved this manuscript. This study was funded by the National Science Foundation.

\section{References}

Agency of Natural Resources and Energy and Geological Survey of Japan, Ministry of International Trade and Industry (1976). Index to the Geothermal Field of Japan, $65 \mathrm{pp}$.

Blom, G. (1989). Probability and Statistics: Theory and Applications, Springer-Verlag, New York, 356.

Brodsky, E. E., and S. G. Prejean (2005). New constraints on mechanisms of remotely triggered seismicity at Long Valley Caldera, J. Geophys. Res. 110, B04302.

Brodsky, E. E., V. Karakostas, and H. Kanamori (2000). A new observation of dynamically triggered regional seismicity: earthquakes in Greece following the August 1999 Izmit, Turkey Earthquake, Geophys. Res. Lett. 27, 2741-2744.

Brodksy, E. E., E. Roeloffs, D. Woodcock, I. Gall, and M. Manga (2003). A mechanism for sustained ground water pressure changes induced by distant earthquakes, J. Geophys. Res. 108, 2390-2400.

Centroid Moment Tensor (CMT) Catalog, www.seismology.harvard.edu/ CMTsearch.html (last accessed October 2005).

Choy, G. L., and J. L. Boatwright (1995). Global patterns of radiated seismic energy and apparent stress, J. Geophys. Res. 100, 18,205-18,228.

Dieterich, J. (1994). A constitutive law for rate of earthquake production and its application to earthquake clustering, J. Geophys. Res. 99, 2601-2618.
Global Volcanism Program, Smithsonian National Museum of National History, www.volcano.si.edu/volcanoes/region08/hokkaido/usu/var. htm\#bgvn_2503 (last accessed December 2005).

Gomberg, J. (2001). Failure of earthquake failure models, J. Geophys. Res. 106, 16,253-16,263.

Gomberg, J., P. Bodin, K. Larsen, and H. Dragert (2004). Earthquake nucleation by transient deformations caused by the $M=7.9$ Denali, Alaska, earthquake, Nature 427, 621-624.

Gomberg, J., P. A. Reasenberg, P. Bodin, and R. A. Harris (2001). Earthquake triggering by seismic waves following the Landers and Hector Mine earthquakes, Nature 411, 462-466.

Hill, D. P., P. A. Reasenberg, A. Michael, W. J. Arabaz, G. Beroza, D. Brumbaugh, J. N. Brune, R. Castro, S. Davis, D. Depolo, W. L. Ellsworth, J. Gomberg, S. Harmsen, L. House, S. M. Jackson, M. J. S. Johnston, L. Jones, R. Keller, S. Malone, L. Munguia, S. Nava, J. C. Pechmann, A. Sanford, R. W. Simpson, R. B. Smith, M. Stark, M. Stickney, A. Vidal, S. Walter, V. Wong, and J. Zollweg (1993). Seismicity remotely triggered by the magnitude 7.3 Landers, California, earthquake, Science 260, 1617-1623.

Husen, S., R. Taylor, R. B. Smith, and H. Healser (2004). Changes in geyser eruption behavior and remotely triggered seismicity in Yellowstone National Park produced by the 2002 M 7.9 Denali Fault earthquake, Alaska, Geology 32, 537-540.

Husker, A. L., and E. E. Brodsky (2004). Triggered seismicity in Idaho and Montana: a window into the geologic context for seismic triggering, Bull. Seism. Soc. Am. 94, S310-S316.

Kato, T., G. S. El-Fiky, and E. N. Oware (1998). Crustal strains in the Japanese Islands as deduced from dense GPS array, Geophys. Res. Lett. 25, 3445-3448.

Kilb, D., J. Gomberg, and P. Bodin (2000). Triggering of earthquake aftershocks by dynamic stresses, Nature $\mathbf{4 0 8}, 570-574$.

Miyazawa, M., and J. J. Mori (2005). Detection of triggered deep lowfrequency events from the 2003 Tokachi-oki earthquake, Geophys. Res. Lett. 32, L10307.

Oike, K., and K. Matsumura (1984). Triggers of earthquake occurrence, Gekkan Chikyu 7, 15-19; (in Japanese).

Prejean, K., D. P. Hill, E. E. Brodsky, S. E. Hough, M. J. S. Johnston, S. D. Malone, D. H. Oppenheimer, A. M. Pitt, and K. B. Richards-Dinger (2004). Remotely triggered seismicity on the United States west coast following the $M_{\mathrm{w}} 7.9$ Denali Fault earthquake, Bull. Seism. Soc. Am. 94, S348-S359.

Scholz, C. H. (2002). The Mechanics of Earthquakes and Faulting, Second Ed., Cambridge U. Press, Cambridge, U.K., 471 pp.

Sibson, R. H. (1974). Frictional constraints on thrust, wrench and normal faults, Nature 249, 542-544.

Ukawa, M., E. Fujita, and T. Kumagai (2002). Remote triggering of microearthquakes at the Iwo-jima volcano, J. Geography 111, 277-286.

Department of Earth and Space Sciences

University of California, Los Angeles

595 Charles Young Drive East

Los Angeles, California 90095-1567

rebecca@moho.ess.ucla.edu

brodsky@ess.ucla.edu

Manuscript received 13 April 2005 